\title{
A DISCUSSION OF THAI STUDENT TEACHERS' EXPERIENCES OF CULTURE SHOCK DURING THEIR STUDY IN INDONESIA
}

\author{
Dinda Fitriana*1, Intan Pradita*2 \\ dinda.fitriana@students.uii.ac.id ${ }^{* 2}$, intan.pradita@uii.ac.id ${ }^{* 2}$ \\ English Language Education Department ${ }^{* 1,2}$ \\ Islamic University of Indonesia ${ }^{* 1,2}$
}

\begin{abstract}
Culture shock tends to be experienced among students who study abroad. Most of the previous studies' studies tend to discuss the importance of intercultural communication competence and only describe the kinds of culture shock. Thus, to fill this empirical void, this study investigates Thai student teachers' experiences of intercultural communication competence and how they handle their culture shock during the study in Indonesia. The study employed a qualitative method. Participants in this research were two Thai student teachers who have lived for more or less 4 years in one of the Islamic universities in Yogyakarta. The finding showed that all participants experienced the culture shock symptoms stages, such as the tension of adaptation, sense of loss and rejection from the environment, rejection of new culture, unpredictable anxiety, and helplessness for the first time they studied in Indonesia. Both of them were lack of intercultural communication competence due to their anxiety.
\end{abstract}

Keywords: Culture Shock Symptoms, Intercultural Communication Competence, Anxiety

DOI: $\underline{\text { https://doi.org/10.31943/wej.v4i2.114 }}$

\section{BACKGROUND OF STUDY}

Current discussion about intercultural communication competence among international students studying abroad signified that intercultural communication competence plays an important role for making them survived and making their study successful. Empirical evidence found that building intercultural competence should involve not only language competence, but also psychological one (Catagay, 2015; Pradita, 2013; Qun, Syihabbudin, Mulyati, 2018), Zhou, Jindal-Snape \& Todman (2008). Further, some studies found that by having less intercultural communication competence, it might lead into culture shock (Pradita, 2013), and even self-distancing (Cagatay, 2015). Some practical evidence highlighted that self distancing practices were also included as culture shock symptoms, such as feeling less comfortable to talk and even suicidal (Qun, Syihabbudin, Mulyati, et al, 2018). Thus, an 
encouragement to develop intercultural communication competence should be conducted.

One of those who were exposed to intercultural communication was international students (Jandt, 2003). By then, they were required to be adaptable through building their intercultural communication competence thoroughly. Intercultural communication competence was known as a skill that is used by people from other country to communicate effectively. Bochner and Furnham (2001) highlighted that such competence would assist an intercultural communicator when we used part of function of our knowledge of others and other cultures. It also gave student understanding about tolerance across culture. Thus, before going abroad, students should learn the culture of the country that they will visit to minimize the culture shock.

Cultural differences play a crucial role in promoting student's competence in English. As in case at one of Islamic universities in Yogyakarta, there are Thai students who study English for 4 (four) years. It is found that the students were still confused to use English or Bahasa in their daily communication with Indonesian students for 2 years. They felt confused how to communicate with Indonesian students effectively with Bahasa, because Indonesia and Thailand have different accent. While study in class they also have to deal with Indonesian letter which is very different with Thailand letter. This research is almost similar with Qun, Syihabbudin, Mulyati, et al, (2018) which discuss about Chinese students ${ }^{\text {ee }}$ culture shock in a university in Indonesia. It is similar to this research in context and in terms of what is examined in their study.

In the previous study on this issues most of the studies tend to discuss the importance of intercultural communication competence or just describe kinds of culture shock (Qun, Syihabbudin, Mulyati, et al., 2018). Rarely do researchers elaborate to what extent intercultural communication competence in accordance with culture shock symptoms. Thus, to fill this empirical void, this research focuses on how intercultural communication competence helps Thai students to survive and overcome their culture shock, and Thai students can communicate in English or Bahasa Indonesia during study in Indonesia. Related to the issues observed, the aim of this study is to investigate Thai students ${ }^{\text {ee }}$ perceptions of intercultural communication competence to deal with their culture shock during study in Indonesia.

\section{RESEARCH QUESTION}

1. How do the Thai students experience symptoms of culture shock during their study?

2. To what extent does intercultural communication competence help Thai students to deal with culture shock symptoms?

\section{LITERATURE REVIEW Aspects of Culture Shock}


Oberg (1960) defined that culture shock refers to unavoidable reactions or feeling when someone faced differences during daily interaction with diverse culture. Through the process of trying to accept new or different cultures, someone who experienced culture shock tend to feel anxious as an effect of losing all our familiar signs and symbols of social intercourse. Culture shock appears when people suddenly move to another country, it includes almost all aspects in their daily life. He states that there are six aspects of culture shock; (1) tension resulting from the effort of psychological adaptation, (2) a sense of loss referring to the rejection from former friends, status, role, and possessions, (3) rejection by the new culture, (4) confusion in the role of definition, expectation, feelings, and self-identity, (5) unpredictable anxiety, disgust regarding cultural differences between the old and new ways, (6) feeling of helplessness as a result of not adapt well in the new environment. The first aspect of culture shock is honeymoon stage. It will happen for a few days, weeks, or months, it depends on their issues. It is usually caused by different language, seeing the new rules or environment. In the second stage, sojourners will feel they are rejected by environment, because they face some problems such as, with their school environment, with the housemate, transportation problem or food problem. Next, the stage of rejection by new culture means, the sojourners still feel difficult to adapt in new environment but still in the process of recovering from the rejection; One of the examples is when someone is joking with their friends and trying to engage in a conversation. The fourth stage, they will feel confused about their existence in the new environment, because their real-life in new culture will be different from their expectation before coming the new country. The fifth stage shows that the anxiety from the differences of the new culture and the old one. For example, when sojourners face differences of how to drink or to eat. The final stage causes depression as the result of sojourners cannot adapt well in new environment.

To deal with culture shock, Oberg (1960) explains that it would be easier to bear with it if the foreign learner tells their story about their discomfort with friend from the home country. The concept of culture shock was continued by Pedersen (1995:1), he stated that culture shock is the first process of adjustment with an unfamiliar environment. He also defines that culture shock in multicultural context is more or less sudden immersion with a nonspecific state of uncertainty. In this case, the individual is not certain of what they should imagine or what can they expect from other people around them. Thus, culture shock in general is such a discomfort feeling that appear when people or sojourners entering the new environment or new culture that is very different from their culture, they do not understand what to do. On the other hand, culture shock, that usually appeared and experienced by learners, leads to negative aspects. Therefore, a good preparation before going abroad for students is very important to face the new culture that they will find, thus, they can minimize those negative aspects. It strengthens by Landis \& Brislin (1983) who suggest that cross-cultural training will encourage better knowledge of other culture and it helps to reduce culture shock. The development of culture shock aspects are not only about how the sojourners work with their own feeling or anxiety, but also how assimilation and acculturation process enable them to cope with the culture shock itself (Zhou, Jindal-Snape \& Todman (2008)). This figure synthesized the concept: 


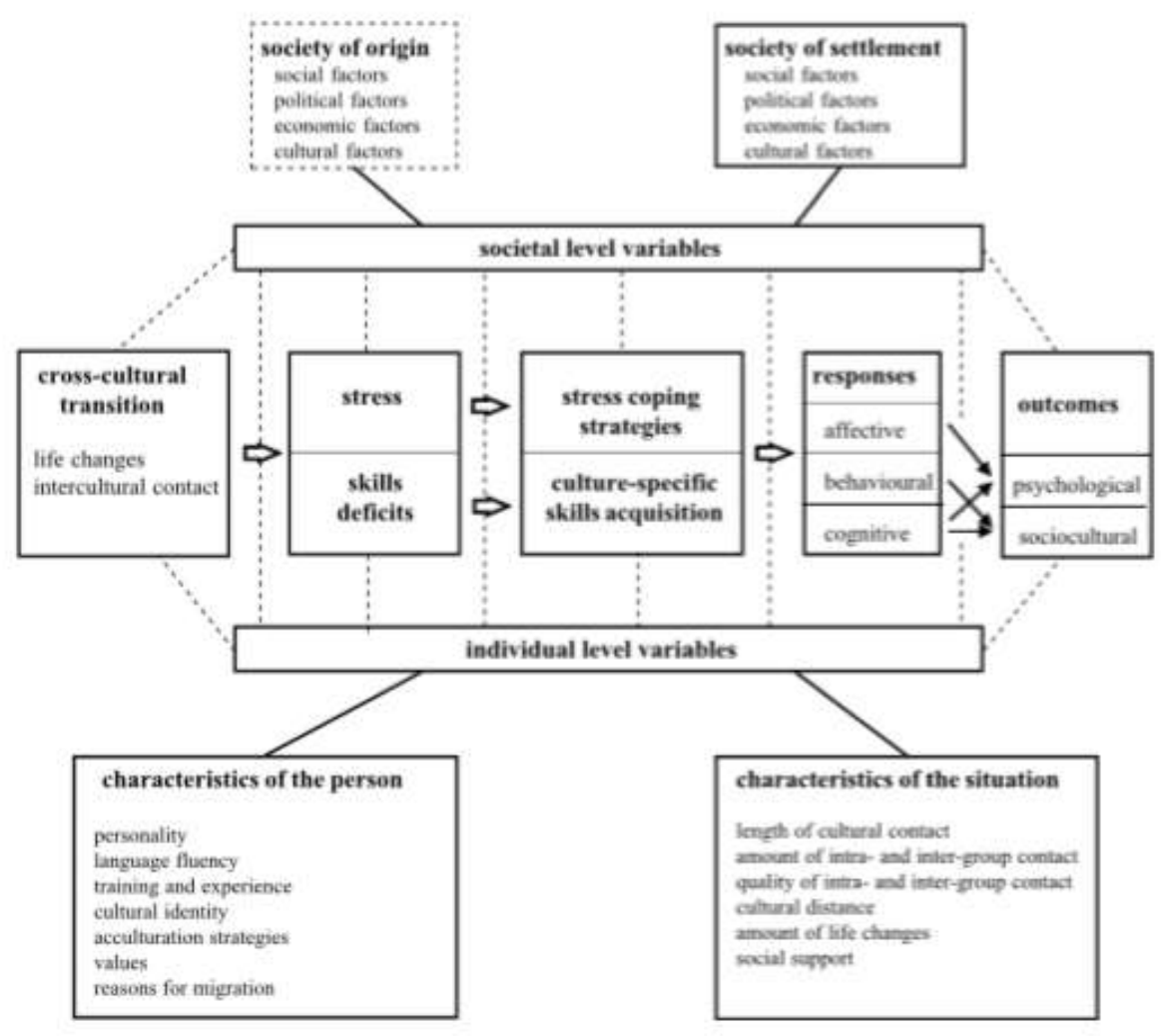

Figure 1. The Acculturation Process during Culture Shock (Adapted from Ward, Bochner and Furnham 2001)

As presented above, Oberg's (1960) aspects of culture shock were perceived to be societal level of variables. In this stage, the sojourners were still focus on what happened outside them. It included cross-cultural transition, which then cause stress and skills deficits. However, through the time, they were able to cope their stress and culture-specific acquisition. Thus, there would be affective responses and be followed up with psychological and sociocultural outcomes. Through then, there would be individual level variables that acculturated and assimilated later on. As Oberg (1960) explained that one of the causes of culture shock is anxiety, and it always happens to sojourners when they are learning in class which consists of many learners from other country. This concept is also supported by Renee (1998)., He claims that learners can feel the anxiety easily when being exposed to foreign language situation. Thus, students in class feel anxious while learning, which means class is one of small scopes that they face. Moreover, when they face new culture in their daily activity, especially to speak with others. With this in mind, foreign language anxiety tends to cause potential problem to learners in their foreign language learning (Chen and Chang, 2004). Mac Intyre and Gardner (1994) state that language anxiety means the feeling of tension and apprehension experienced by the learners. Furthermore, Pappamihiel (2002) divides the anxiety into two types: the first one is a type which occurs because learners are exposed to particular situation, and the other type is a trait 
anxiety of students" tendency to feel anxious regardless of the situation to which they faced. Dörnyei (2005) also adds that the two important anxiety classifications are usually effective in literature: Beneficial/facilitating and debilitating anxiety. Beneficial anxiety causes the action and excitement, and it smoothest the way for success, and debilitating one, is places a divider in front of a successful performance.

The other cause of culture shock is due to the lack of intercultural communication competence. To develop intercultural competence, it focuses only language itself, in education the focus is naturally on knowledge-history, literature, language, music, product of culture (Darla, 2009). To this extent, intercultural communication competence has important roles to minimize the culture shock. Thus, background knowledge and preparation related to intercultural communication competence are needed by sojourners before going abroad.

\section{International Students Experience about Culture Shock}

The empirical studies about students"e experience in culture shock while studying abroad present various result. The study from Xiaqiong (2008) and Macionis, Walters, \& Kwok (2018) discuss a case of Asians students from China and Singapore who studied abroad in Australia showed the difficulties to adjust in living in Australia and they are discriminated by their race, because most of them were Chinese (Macionis, Walters, \& Kwok, 2018). The students from Singapore were also chinese. They shared their experiences when they were being rejected by Australian in terms of their daily life, while they used public transportation, and street violence. The form of rejection that they had was when Australian people stared at the Singaporean and the worst thing was they threw eggs to them. Moreover, they were little bit shy to speak up in class, or to ask a question to lecturer, not like the Australian students, they were brave to share their opinion in class. On the other hand, a study done by Lin (2006) and Anderson \& Maginnis (2017) tells about international students from different country who studied in United States also experiencing culture shock in many aspects, the barrier of language to speak with American, difficulty to adapt in new surroundings, and adjustment in class with American students. Nevertheless, not only sojourners or tourist who experienced culture shock, the workers who worked worldwide also experienced that symptoms. The study of Lee (2016) shows that British worker who mutated their work in an art company in Australia also experienced culture shock, she felt difficult as a manager to make a deal with Australian and how to manage her subordinates.

\section{RESEARCH METHOD}

Since our university issued world class curriculum, we accepted some international students to study English in our department. The first international students were from Thailand who performed to be struggling in accomplishing both cognitive and communicative competence. However, the participants in this research remained committed to the additional programs made by our department and our university. Those programs included bahasa Indonesia course and special English course. One of the researchers were their classmate and the other one was their lecturer. During the whole interaction in four years, we often belonged to those 
additional programs. Thus, it was such a close relationship that we could documented their experiences in dealing with culture shock during their study in Indonesia. This study employed case study design. (Yin, 2004). This study was designed to investigate Thai students'experiences of intercultural communication competence to deal with their culture shock during their study in Indonesia.

\section{Research Setting and Participants}

The participants of this research were two Thai students of English language education department at an Islamic university in Yogyakarta. After signing the consent form, both of them agreed to be interviewed. Their privacy was under the consent of our department. The researcher chose two Thai students from the length of study and from the academic records of both participants. They have lived for more or less 4 years in Indonesia. There were Andi and Ana (pseudonym) who were recruited as participants in this research. They had similar opportunity to study in Indonesia, the first one is Andi who has lived for almost 4 years in Indonesia, at the first time his study he lived in a male dormitory as facility that the university gave to him because he was a scholarship grantee, after 3 years, he decided to move with his friends to live in a boarding house because he cannot follow the dormitory rules, whereas the dormitory requires all of students in the dormitory to follow the additional class there. The second one is Ana who has lived for 3 years, she lived in a female dormitory in the university area because she is a scholarship grantee. They were also good in coping with academic competence proven by their IPK. At their first year study, they got medium range of score and in the second years, their score getting higher and higher in the next year, and also they were often available in campus. By considering Oberg's (1960) description about the nature of international students, thus, the participants are mentioned as sojourners.

\section{Technique of Data Collection \& Research Instrument}

The instrument that we used in this research was in-depth interview. We used a structured interview which the research question that had been formed before the interview session. This in-depth interview would state the students experience during their study in Indonesia. The interview session was conducted one-by-one interview where we would interview face to face in different place and time. Then the whole process were was recorded by voice recording or video recording. We only used interview as a main source data (Othman, et al., 2018). Cresswell (2013) in Othman, et al., (2018) states that in-depth interview in qualitative research is very important and it is reputable as an effective way to get the legality as a trustworthiness of the data, beside the observation or survey in a progressing study. The interview was done in one time with the participant. The interview with Ana was done on Saturday, 06th of July 2019 around 02.00 PM at female dormitory around the university, and interview with Andi was done on Sunday, 07th of July 2019 around 12.00 PM by chat using voice note.

\section{Data Analysis}

In analyzing qualitative data, Creswell (2012) explains that the researchers develop a general sense of the data and then they code description and themes about 
central phenomenon. Cresswell (2013 adds that in depth/profound interview, it is very important and reputable as an effective way to gain deeper analysis, researcher using thematic analysis that is one of method which used identifying, analyzing, and reporting patterns of themes in data and it minimally organizes and describes the data set in detail (Braun \& Clarke, 2006). There are six phases/steps of thematic analysis as represented in the activities below:

We transcribed the result of the interview, and reading all the source of the data shown in the transcription of verbal data. We selected the data that were relevant to be codified. We used colors and initial coding to analyze the data. Each of us revieweing one another so that we made peer debriefing. Some analysis were improperly codified or found to be with similar coding. However, we tended to negotiate which process that were match one another. After having proper coding, we tried to group them into generated themes. We then discuss the encryptions by using thematic analysis. We tried to find theoretical and empirical relationship between our data findings and the existing theory or previous studies. The method of this research has been published, confirmed, and reviewed in a journal as trustworthiness. The credibility of the method has been reviewed by the expert judgement with one of lecture, as Widodo (2014) suggests that the data should be confirmed or communicated to verify the credibility. It can be seen in appendices 3 and 4.

\section{Findings}

The result of the data that the authors gains from the interview shows that both sojourners experienced the symptoms of culture shock in the form of tension of adaptation, sense of loss and rejection, rejection by new culture, unpredictable anxiety, and feeling of helplessness. However, the sojourners did not experience confusion in their self-identity due to their ability to set their goals in Indonesia. Based on Braun and Clark (2006), the use of thematic analysis as a method is to identify, analyze, and report the patterns (themes) with the data. As the researcher's coding data, not all coding appeared in the data, there are also emergent findings in the data. The themes certainly are not always the whole coding. Thus, Braun and Clark (2006) highlighted that researcher needs to attach the theoretical commitments from grounded theory.

\section{Discussion}

\section{A. Culture Shock Symptoms during the Sojourners' Study (Societal Level Variables)}

By considering the ground theory by Oberg (1960), the culture shock components tend to happen in Thai students who study in Indonesia. As the findings here tend to correspond with most of the culture shock component as constructed by Oberg (1960). The themes of culture shock construct are (i) tension of adaptation, (ii) sense of loss and rejection from environment, (iii) rejection by new culture, (iv) confusion in the expression and self-identity, (v) unpredictable anxiety, (vi) feeling of helplessness because cannot adapt well, and also (vii) intercultural communication competence as emergence findings. 


\section{(i). Tension of adaptation}

The finding of this aspect shows that the Thai students experienced tension of adaptation at their first time study in Indonesia. This result is in lined with Oberg (1960) theory about aspect of culture shock. He explained that tension resulting from the effort of psychological adaptation and it is called as honeymoon stage. It will happen for a few days, weeks, or months, it depends on their issues. It is usually caused by having different language, seeing the new rules or environment.

I think it's about food and language, because the language is important. First, I can't speak in Bahasa. However, I should able to speak, so I always listen other people if they are speaking then, I can join with my friends. Second, it's about food, I can't eat properly at the first time. CS/TA/011/AI

Which makes me shock is just about the culture, like when I was in Pesta there was a concert, I was very shock, this is an Islamic university, but there was a concert, and the other is to be closed with male friends, that's all. CS/TA/018/AA

From the data above, both Andi and Ana experienced the tension and difficulties how to communicate with other. This happened because they have no idea about Bahasa Indonesia before, they see differences in the environment. Andi experienced the tension when he wanted to speak with Indonesian students. While, Ana experienced the tension when she was in an event which was orientation phase. In Thailand she lived in Islamic area, thus, she rarely found a concert, or came to that concert.

(ii). Sense of loss and rejection from environment

The second aspect is sense of loss referring to rejection from former friends, status, role, and possessions. Oberg (1960) explains that in this aspect, sojourners will feel they are rejected by environment, because they face some problems such as, problem in their school, with the housemate, with transportation or food. From this explanation, all of the respondents told their experience and statement that they felt rejected by the environment. This can be seen from:

I think the hardest thing is how to live in Indonesia, because the way to join/engage with friend was difficult, how to eat properly was hard, all of the problem were caused of language. Because, at the first time I arrived here, I can't speak, I didn't understand the language. This experience was too hard. CS/SLR/001/AI

Mmmm, I usually use Thai language more, because I have friend from Thailand here. So, I pretend to always with them. Even I'm in a room with Indonesian, but I'm not usually speak with her. Also in the campus, I rare to speak with Indonesian, except to doing my group task. CS/SLR/003/AA 
at the first time of my study the lecturer use English or Bahasa as language of instruction. so, if I want to do my task, I have to translate it into Thai language. CS/SLR/002/AA

From the statements above, Ana and Andi experienced difficulties in language (Oberg, 1960) and the way to communicate properly with Indonesian. Thus, they felt like they were rejected, and not able to cope with Indonesian. They prefer to communicate and hangout with Thai students. These statements are in line with Oberg's (1960) theory that the sojourners will have sense of loss and rejection from the environment after the honeymoon stage which happened around the first six months of their stay. The situation is like the Indonesian reject them because either the Indonesian students or the lecturer did not understand Thai language, thus the sojourners feel like they were discriminated. The other empirical studies from Xiaqiong (2008) proves that Chinese students who studied in Australia had difficulties to adjust living in Australia. They were discriminated by their race while they were in a bus and they were thrown with eggs by Australian people.

(iii). Rejection by new culture

In Xiaqiong (2008) found that the Chinese students felt they were rejected by the family in that country. There were differences on how to cook the rice. All of respondent that were interviewed by the researcher also experienced this stage in different situation. One of the respondents experienced this stage when he went out with his friend, the other one experienced it in the classroom. This can be seen from the statement below:

For example, in the learning process at the classroom, if I don't understand, I have a friend who take the same major with me, and same department, so I will ask her directly, or with the senior. If I had a problem I directly ask them. CS/RNC/004/AA

Hmmm, if there is something that I don't like or I don't interest with, I will not follow it or take it. For example, if my Indonesian friends ask me to hangout to get some coffee till midnight, I join them sometimes, because actually I don't really like coffee, and hangout till late at night. So, usually I ask my friend's permission to go back to dorm earlier, or I reject their invitation. CS/RNC/004/AI

Based on the result above, there is difference between Indonesian culture and Thailand culture. Ana said that she usually feels rejected in classroom situation, and Andi usually get difficulties when he went out with his friend. Those, are in line with Obergees (1960) explanation about the third stages of culture shock. Rejection by new culture means the sojourners still feel difficult to adapt in a new environment but still in the process of recovering from the rejection, as an example is when someone is joking with their friends and the sojourners want to engage in that conversation. In this phase actually, as Oberg explained that the environment did not really reject 
them, but the sojourners just feel like rejected by the environment, it tends to reject of a new culture.

(iv). Confusion in the expression and self-identity

In this theme, all of the respondents did not experience confusion of their roles and their identities. The data shows that all sojourners had a goal, and knew what they have to do during their studies. Meanwhile, Oberg (1960) states in this stage, they will feel confused about their existence in a new environment, their real-life in new culture will be different from their expectation before coming the new country. It can be seen from statement below:

Oohh, no I don't. So, at the first time I was here I already know about my job here, what I have to do here, because the major that I chose is my favorite. But just the English, not education. So, while I already in 6th semester now, so I have to think about my future "am I want to be a teacher?" because actually I don't really like to be a teacher, so I just chose because there is English here, and it closer to PPL program, so I like to be a teacher, I will be a teacher soon. CS/CR/007/AA

I think I have so many goals, in my study I will be a teacher, besides that, I will get so much life experience, I can do a job, like I be a guide for my Thailand friends to traveling in Indonesia. I think it's very good to me. CS/CR/006/AI

From the data above, the sojourners clearly state that they already have a goal and know their role during their study in Indonesia. They already had some preparation before they are going abroad to continue the bachelor degree after finishing senior high school. Both of them had a goal to be a teacher in the future after they finish their study in Indonesia.

(v). Unpredictable anxiety

For unpredictable anxiety stage of the Thai students, they experienced this stage. It is affected by the local language and daily language that is used by Indonesian. It can be seen from the statement below:

Usually, if I didn't really know the meaning of the words, I translated it by using my smartphone, or ask the meaning to my friends. If it was very difficult I just changed the topic. CS/UA/008/AA

For example, the Javanese language itself like "piye kabare", I really didn't understand for the first time, so I asked my friends to explain it to me, what the meaning is, then my friends explain what the meaning of "piye kabare". CS/UA/008/AI 
Oberg (1960) explains that in this stage the sojourners show anxiety from differences in the new culture and the old one. For example, if the sojourners face differences of how to drink or to eat. The data shows that it is in line with Oberge's (1960) theory, but, for Thai students, they had difficulties in ways of communication. They tried to always cope and fight their anxieties to speak and communicate with others.

(vi). Feeling of helplessness because they cannot adapt well

In this stage, the data shows that not all Thai students had experienced this situation. It is just Ana who experienced this stage sometimes. Meanwhile, Andi could enjoy his friendship. It can be seen from the encryption below:

Sometimes, if there is a task from teacher. Sometimes, my friend already explains that but I'm not understand yet. Then, I think that I am a college student, so I have to attempt by myself. Sometimes, I think this is so hard, and I feel hopeless, also I think that is it true for me to continue my study in Indonesia... CS/FHS/012/AA

I think the culture is good for me, if there is good for me so I follow that, if not, I just leave it. I just have to adjust myself. CS/FHS/009/AI

From the data above, it is in line with Oberg (1960) who explains that in this stage the cause of depression is the result of sojourners cannot adapt well in a new environment. It is proven by Ana statement that she explained that it is very hard to study in Indonesia and she doubt her option to study in Indonesia. Meanwhile, Andi is more flexible to adapt in Indonesia, he can adapt well in Indonesia and accept the new culture.

\section{Intercultural Communication Competence (Individual Level Variables)}

(vii). Intercultural Communication Competence

From the result of interview, the Thai students talked more about their anxiety in language and food. The data shows that at the first time, they had difficulty to communicate with others and how to eat properly in Indonesia, because between Indonesia especially Yogyakarta and Thailand have different taste of food. It can be seen from the statement below:

If we understand the language, we can do anything. We can join with friends, we can go anywhere easily. ICC/002/AI

At the first time, I can't speak Bahasa at all, so I used body language, and I just understood little bit, because in Thailand, I live in South of the Thai that using malay language. ICC/001/AA

And also the food is different, the taste is little bit different from my hometown ICC/011/AA 
How it feels ya? Because it's different. In Jogja, almost all food taste so sweet, in my hometown it tastes spicy and sour. So, I have to try to eat and eat, I force myself till I could eat all that food. ICC/012/AI

From the data above, it shows the same result that they had difficulty to speak and eat in Indonesia. Meanwhile, Intercultural communication competence itself is a skill to communicate with other people from different country effectively (Jandt, 2003). It is in line with Darla (2009) who explains that, to develop the intercultural competence is not enough just from the language itself, in education, people need to focus naturally on knowledgehistory, literature, language, music, product of culture. Moreover, it is also in line with Jandt (2003) who describes the one of importance of ICC skills, if we learn more about people from different culture, we also find more about ourselves.

\section{B. Anxiety that cause the culture shock symptoms}

As Oberg (1960) explains that the cause of culture shock is anxiety, and it always happens to sojourners when they are learning in class which consists of many learners from other country. Then, Dörnyei (2005) describes the two important anxiety classifications which are usually effective in literature, there are debilitating anxiety and beneficial anxiety. In this themes, each participant experienced the anxiety and both of them pretended to show the beneficial anxiety. It can be seen from below statements:

Keep spirit, I have to (be able to adapt in Indonesia)

\section{A/BA/012/AI}

In the past I wasn't brave enough to come in front of class, to asking question, if the lecture ask me, I couldn't answer it. But, now I can do that, I have to be brave and push myself. If the lecture asks me, I can answer the question. A/BA/015/AA

From the data above, it proves that anxiety leads them to be brave and strong to survive in Indonesia, during their study in Indonesia. It is in line with Dörnyei (2005) who explains that beneficial anxiety is cause the action, excitement, and it is fluence the way to a success. Both Andi and Ana showed that they have already survived in Indonesia for more or less 3 years in Indonesia. Besides that, Ana also experienced the debilitating anxiety at the first year her study in Indonesia. It can be seen from:

If I asked to come in front of the class, I was afraid. Because Indonesian students are very brave, they brave to speak in front of the class, while I was so scared to speak in front of the class because the lack of my language skill. A/DA/013/AA 
The data shows that Ana was afraid and scared to speak in front of class, and also very shy to speak. Her anxiety made her afraid to take her roles in the class. So, it is in line with another classification of anxiety from Dörnyei (2005), that is debilitating anxiety. He defines that debilitating anxiety is a divider in front of a successful performance, and it affects Ana performance in class. Moreover, this data shows that the debilitating anxiety is also in line with study from Matusitz (2015), he found that Asian student who studied in America showed their difficulties in term of barrier of language to speak with American, and how to adapt in class with American students.

\section{CONCLUSION}

From the findings of this research, we conclude that all of respondents showed culture shock aspects. The themes that appeared were tension of adaptation, sense of loss and rejection from new culture, rejection by new culture, unpredictable anxiety, feeling of helplessness. The other thing that we can conclude is that, both of Thai students had intercultural communication competence issue, and from the anxiety, the sojourners accepted it as positive issue that was used to survive and made them stronger. The culture shock symptoms and intercultural communication competence issue gave impact to the sojourners at their first time study in Indonesia and their cognitive competencies in the classroom. Thus, it is expected to add more knowledge of the sojourners if they are in a foreign country as implication of this study. This research is limited to investigate Thai students' perceptions of intercultural communication competence to deal with their culture shock during study in Indonesia especially in an Islamic university of Indonesia. As implication of this study, it is better for sojourners to have background knowledge about the country that the sojourners choose.

\section{REFERENCES}

Braun, V., \& Clarke, V. (2006). Using Thematic Analysis in Psychology. Qualitative research in Psychology, 3(2), 77-101.

Creswell, J. W. (2013). Research Design: Qualitative, Quantitative and Mixed Methods Approaches 4th edition. California: Sage Publication.

Darla, D. K. (2009). Intercultural Competence. California: Sage Publication.

Dörnyei, Z. (2005). The psychology of the language learner: Individual differences in second language acquisition. New Jersey: Lawrence Erlbaum Associates, Inc.

Fred, E. J. (2003). Intercultural Communication, An Introduction. London: Sage Publication.

Lee, K. (2016). Crossing borders with youth arts in a remote Australian community. $N J, 40(1), 40-52$. 
Lin, C. (2006). Culture Shock and Social Support: An Investigation of A Chinese Student Organization on an US Campus. Journal of Intercultural Communication Research, 35(2), 117-137.

MacIntyre, P. D., \& Gardner, R. C. (1994). The subtle effects of language anxiety on cognitive processing in the second language. Language learning, 44(2), 283305.

Macionis, N., Walters, G., \& Kwok, E. (2019). International tertiary student experience in Australia: A Singaporean perspective. Journal of Hospitality, Leisure, Sport \& Tourism Education, 25 (1). 1-10..

Maginnis, C., \& Anderson, J. (2017). A discussion of nursing students' experiences of culture shock during an international clinical placement and the clinical facilitators' role. Contemporary nurse, 53(3), 348-354.

Matusitz, J. (2015). The Acculturative Experience of French Students in a Southwestern University Apartment Complex in the United States. Journal of Human Bahvior in the Social Environment, 25(15), 261-274.

Oberg, K. (1960). Cultural shock: Adjustment to new cultural environments. Practical Anthropology, (4), 177-182.

Othman, I. W., Awang, H., Hamid, A. A., Yusoff, S. M., \& Jupiter, H. (2018). The Study of First Year International Students' Expatriate Experiences in University of Malaysia Sabah. Journal of Tourism, Hospitality and Environment Management, 3(8), 34-43.

Pappamihiel, N. E. (2002). English as a Second Language Students and English Language Anxiety: Issues in the Mainstream Classroom. Proquest Education Journal, 36(3), 327-355.

Pedersen, P. (1995). The Five Stages of Culture Shock: Critical Incidents around the World. London: Greenwood Press.

Pradita, I. (2013). A Case Study of Forms and Symptoms of Culture Shock of the Foreign Students in Yogyakarta. Journal of English and Education, 7 (1), 113.

Qun, W., Syihabuddin, S., Mulyati, Y., \& Damaianti, V. (2018). Perceiving and Dealing with Culture Shock: The Study of Chinese Indonesian-Language Students. International Journal of Education, 11(1), 18-26. https://www.learntechlib.org/p/208939/.

Widodo, H. P. (2014). Methodological Considerations in Interview Data Transcription. International Journal of Innovation in English Language, 3(1), 101-107. 
Xiaoqiong, H. (2008). The Culture Shock that Asian Students Experience in Immersion Education. Changing English, 15(1), 101-105. http://dx.doi.org/10.1080/13586840701825378

Zhou, Y., Jindal-Snape, D., Topping, K., \& Todman, J. (2008). Theoretical models of culture shock and adaptation in international students in higher education. Studies in higher education, 33(1), 63-75. 